Article

\title{
Ventilatory Function in Young Adults and Dietary Antioxidant Intake
}

\author{
Vanessa Garcia-Larsen ${ }^{1,2, *}$, Hugo Amigo ${ }^{3}$, Patricia Bustos ${ }^{3}$, Ioannis Bakolis ${ }^{4}$ and \\ Roberto J. Rona ${ }^{5}$
}

1 Respiratory Epidemiology, Occupational Medicine, and Public Health Group, National Heart \& Lung Institute, Imperial College London, London, SW3 6LR, UK

2 Royal Brompton Hospital and Harefield NHS Foundation Trust, Sydney Street, London SW3 6NP, UK

3 Department of Nutrition, Faculty of Medicine, University of Chile, Independencia 1027, Santiago, Chile; E-Mails: hamigo@med.uchile.cl (H.A.); pbustos@med.uchile.cl (P.B.)

4 MRC-HPA Centre for Environment and Health, Department of Epidemiology and Biostatistics, Imperial College London, London, W2 1NY, UK; E-Mail: i.bakolis@imperial.ac.uk

5 Department of Psychological Medicine, Weston Education Centre, King's College, London, SE5 9RJ, UK; E-Mail: roberto.rona@kcl.ac.uk

* Author to whom correspondence should be addressed; E-Mail: v.garcialarsen@imperial.ac.uk; Tel.: +0044-020-75947495; Fax: +0044-020-73528122.

Received: 17 November 2014 / Accepted: 26 March 2015 / Published: 15 April 2015

Abstract: Dietary antioxidants may protect against poor ventilatory function. We assessed the relation between ventilatory function and antioxidant components of diet in young Chileans. Forced expiratory volume in $1 \mathrm{~s}\left(\mathrm{FEV}_{1}\right)$, forced vital capacity (FVC), and the ratio $\mathrm{FEV}_{1} / \mathrm{FVC}$ were measured in 1232 adults aged 22-28 years, using a Vitalograph device. Dietary intake was ascertained with a food frequency questionnaire (FFQ) designed for this study, from which nutrient and flavonoid intakes were estimated. Dietary patterns were derived with Principal Component Analysis (PCA). After controlling for potential confounders, dietary intake of total catechins was positively associated with FVC (Regression coefficient (RC) of highest vs. lowest quintile of intake 0.07 ; 95\% CI 0.01 to 0.15 ; $p$ per trend 0.006). Total fruit intake was related to FVC (RC of highest vs. lowest quintile 0.08 ; $95 \%$ CI 0.003 to 0.15 ; $p$ per trend 0.02 ). Intake of omega 3 fatty acids was associated with a higher $\mathrm{FEV}_{1}$ (RC for highest vs. lowest quintile 0.08; 95\% CI 0.01 to $0.15 \mathrm{~L}$; $p$ per trend 0.02) and with FVC 0.08 (RC in highest vs. lowest quintile of intake 0.08, 95\% CI 0.001 to 0.16; $p$ per trend 0.04). Our results show that fresh fruits, flavonoids, and 
omega 3 fatty acids may contribute to maintain ventilatory function.

Keywords: antioxidants; flavonoids; FFQ; lung function; young adults; general population

\section{Introduction}

Maintenance of ventilatory function in young adults is important to reduce the risk of its excessive decline later in life [1]. Ventilatory function, measured by forced expiratory volume in one second (FEV 1 ) or forced vital capacity (FVC), is a strong predictor of all-cause [2] and cardiovascular mortality $[3,4]$. Similarly, poor ventilatory function in adults has been related to the development of chronic obstructive pulmonary disease (COPD), which currently represents the third cause of mortality worldwide [5].

Dietary intake might contribute to the preservation of ventilatory function in adults. Observational studies suggest that a higher dietary intake of antioxidants, or a diet rich in fresh vegetables and fruits, is associated with better lung function in the general population [6-10]. Epidemiological studies looking at the effect of the whole diet (dietary patterns) have shown that intake of a diet rich in fruit, vegetable, fish, and wholemeal cereal (referred to by some as a "prudent diet") is related to a better ventilatory function [11]. Most studies however, have explored either the association with single nutrients, small food groups or dietary patterns, which can limit the scope of interpretation of the effect of diet on lung health.

Chile is a country where the prevalence of chronic respiratory diseases is similar to that observed in more developed nations [12], but that like other South American countries, dietary customs and the availability of food may differ from those of Europe and the United States. To date no evidence has been obtained on the possible association between dietary antioxidants and measures of ventilatory function in adults from Latin America. Investigating the possible protective effect of dietary antioxidants on lung health in young adults might provide evidence on early prevention of rapid ventilatory function decline later in life.

This study investigates the association between ventilatory function (spirometry) and dietary intake of antioxidant nutrients in a representative sample of young adults from Central Chile. We explored this association at nutrient, food and whole diet level. For the latter, using Principal Component Analysis (PCA) we aimed to investigate two established hypothesis in the field of diet and lung function: an a priori approach of an association of dietary antioxidants with lung function, as well as a posterior approach in terms of an association of dietary patterns with lung function.

\section{Methods}

\subsection{Setting and Sample}

The study took place in Limache and Olmue, situated in the Central valley of Chile, $141 \mathrm{~km}$ from Santiago, with a population of 50,000 inhabitants. Agriculture was the main economic activity in the area at the time of this study, which was carried out between January 2001 and April 2003. The current cross-sectional study is part of a non-concurrent longitudinal study aimed at assessing risk factors for 
asthma in early childhood and in young adults (22-28 years old) an area where they had preserved prenatal and paediatric records on the growth and development of the children [13].

A sampling frame of 3096 individuals, corresponding to all the births in the Hospital of Limache between 1974 and 1978 was obtained. A simple random sample of 1232 subjects was obtained to investigate poor lung function based on statistical power estimates using the effects of birth weight differences on lung function as outcome. Those who could not be included in the study because of death (3.2\%), emigration (11.3\%), serving a custodial sentence, disability or lactation (3.3\%) and unwillingness to participate (7\%) were randomly replaced using the same sampling frame [13].

\subsection{Ventilatory function}

FEV $_{1}$ and FVC were measured in 2001 by trained nurses, using a Vitalograph device model 2120 Spirotrac IV (Buckingham, UK). These measurements were performed following the recommendations of the American Thoracic Society (1987) from which reference values for Chilean adults have been previously derived [14]. FEV 1 as percentage of predicted value was based on Knudson and colleagues' recommendations [15]. Any participant who was unable to produce two technically satisfactory manoeuvres after nine attempts was excluded from the study [16]. The highest value for FEV 1 and FVC produced in up to five satisfactory measures was used in the analyses.

\subsection{Dietary Exposures}

\subsubsection{Food Frequency Questionnaire (FFQ)}

The consumption of 65 food items was assessed in 2001 through the use of a semi-quantitative FFQ designed for this study. The FFQ included a range of staple foods, antioxidant-rich fruits and vegetables, and foods rich in saturated and long chain fatty acids, representing approximately $90 \%$ of foods commonly consumed in the Chilean population [17]. The FFQ used in this cross-sectional study was specifically designed to ascertain intake of dietary sources of antioxidants in the Limache cohort and was internally against a repeated $24 \mathrm{~h}$ recall questionnaire. The FFQ enquired on average food portion sizes. We report total fruit and vegetable intake, which was obtained from converting the reported portions into daily grams. Data on these foods is reported as daily grams.

None of the participants reported taking nutritional supplements. The fieldworkers who administered the questionnaire were unaware of the antioxidant hypothesis being tested, thus diminishing the risk of information bias.

\subsubsection{Nutrient and Antioxidant Estimates}

Nutrient estimates were obtained through SofNut software [18] based on The Nutrient Database of the United States Department of Agriculture (USDA), and on the Chilean Chemical Food Composition Table. We previously examined the levels of agreement between the two Tables, and found these were high to excellent for most nutrients, with the exception of polyunsaturated fatty acids (PUFA) were the agreement was moderate [19].

Flavonoid content of foods was estimated using Dutch food composition data [20] as local tables on these compounds were not available. Three major classes of flavonoids were assessed: flavonols, 
flavones and catechins. Fruits and vegetables rich in antioxidants and vitamins were grouped and their total intake analysed. Total daily intakes of orange, apple, kiwi, strawberry, and mandarin were summed and defined as "total fruit intake". For "total vegetable intake", daily total intake (grams) of commonly consumed food items in Chile was considered, namely tomato, potato, pumpkin, carrot, avocado, garlic, onion, beetroot, chard, and sweet pepper.

\subsubsection{Assessment of Dietary Patterns}

Dietary patterns were identified using principal component analysis (PCA). A varimax rotation was applied to improve the interpretability of the patterns obtained. The number of patterns was determined by examination of the scree plot of the eigenvalues. This is a plot of the eigenvalues $v s$. the component number. The aim was to identify an "elbow" which corresponds to the point after which the addition of more components explains relatively little more of the variance. The scree plot from the PCA showed a clear break in the curve after the second component revealing the presence of two dietary patterns (Figure A1 in Appendix). We additionally considered three components but the two first dietary patterns were included in the main analysis as these were the two more clearly differentiated. The PCA was run with all the 65 foods of the FFQ, and a component score was created for each individual for each of the principal components identified. Individual foods that correlated $>0.3$ or $<-0.3$ with the varimax rotated dietary patterns (principal components) constituted the dietary pattern (Table A1 in Appendix). Principal component scores were converted into z scores and presented as quintiles to provide a more meaningful interpretation of the results.

\subsection{Statistical Analyses}

Estimates of nutrient intake, BMI and adult weight were expressed in median (inter-quartile range). The rest of the descriptive statistics are presented as means \pm standard deviations (SDs).

Maximal FEV 1 and FVC were the primary outcomes of interest and were analysed as continuous variables. FEV $/$ FVC ratio was also analysed. Food and nutrient/antioxidant variables were analysed as quintile groups in order to make comparisons between highest and lowest levels of intake. With regards to flavonoids, quercetin (the main flavonol) was very highly correlated with total flavonol intake, and therefore flavonols were analysed as a group only. Similarly, as intake of epicatechin was highly correlated with catechins and total catechins (the three main contributors to the intake of total catechins in this study), the analyses are presented as total catechins. Dietary pattern scores and grouped daily (g) intake of fruits and vegetables were also analysed as quintiles.

Multivariable linear regression analysis was used to test associations between ventilatory function outcomes (FEV $1, F V C$ and $\mathrm{FEV}_{1} / \mathrm{FVC}$ ratio) and dietary exposures. All models were adjusted for height, sex, age, current smoking, overcrowding, years of fulltime education, socio-economic status, birth weight, body mass index (BMI), and total energy intake (TEI). Socio-economic status in this population was based on indicators appropriate to young adults in Chile as previously reported for this population [21]. Dietary patterns were also adjusted for the effect of each other, as although principal components are uncorrelated, rotations (even orthogonal rotations) can introduce correlations between the patterns. All the dietary exposures were tested for departure from linearity in relation to each of the lung function outcomes with the use of a test for trend. In the current analysis, wheeze or 
bronchial-hyper-responsiveness (BHR) did not alter the direction of the results observed, and therefore these variables were not included as confounders.

Effect estimates are presented as $\beta$-coefficients and 95\% confidence intervals. A $p$-value $<0.05$ was considered to be statistically significant. All analyses were carried out using STATA 12.1 (College Station, Texas, TX 77845, USA). Simes' procedure was used to explore which associations (if any) remained statistically significant after controlling for multiple comparisons [22].

\section{Results}

Of the 1232 participants, 1187 (96.3\%) produced a satisfactory manoeuvre for FEV $\mathrm{F}_{1}$ and FVC, and had complete FFQ data. The mean BMI was $24.6 \mathrm{~kg} / \mathrm{m}^{2}$ and $24.7 \mathrm{~kg} / \mathrm{m}^{2}$ in men and women, respectively. Smoking was common, with over two thirds of males and half of females reporting being current smokers (Table 1).

The average TEI was above the estimated average recommendation (EAR) per day. Carbohydrates were the main source of energy, accounting for nearly $60 \%$ of TEI in both men and women (Table 2). Total lipid intake represented a quarter of the TEI. The intake ratio of omega 6 to omega 3 was 33:1. The average intake of total fruits and vegetables was equivalent to 2 and 4 portions per day, respectively. Intake of antioxidant vitamins and minerals was within recommended values. Intake of vitamins and minerals met the daily recommended nutritional intake (RNI) with the exception of selenium that was $82 \%$ and $50 \%$ of the RNI in men and women, respectively.

The association between outcomes of ventilatory function and intake of flavonoids, antioxidant nutrients and polyunsaturated fatty acids (omega 3 and omega 6) is shown in Table 3. A better FEV 1 and FVC were positively associated with intake of omega 3 fatty acids ( $\beta$-coefficient for highest $v s$. lowest quintile of omega 3 intake 0.08 (L); $95 \%$ confidence interval 0.005 to 0.15 ; and $\beta$-coefficient 0.08 (L), 95\% confidence interval 0.001 to 0.16 ), respectively. An $80 \mathrm{~mL}$ higher FVC was observed in those in the highest vs. the lowest quintile of total flavonols, whilst a $70 \mathrm{~mL}$ higher FVC was observed in those in the highest quintile of catechin intake compared to the lowest (adjusted $p$ per trend 0.006). There was no clear association between the spirometric outcomes studied and antioxidant vitamins or minerals.

Table 4 shows the association between ventilatory function and intake of fruits and vegetables. We found a statistically significantly positive relationship between FVC and total intake of fruits ( $\beta$-coefficient 0.08 ; 95\% confidence interval 0.003 to 0.15 ). No associations were observed between spirometric outcomes and total intake of vegetables. After controlling for multiple testing (Simes' procedure) only the associations between FVC with total fruit intake, and with catechins remained statistically significant. 
Table 1. General and respiratory characteristics of participants.

\begin{tabular}{|c|c|c|}
\hline Variable & Males $(n=542)$ & Females $(n=645)$ \\
\hline \multicolumn{3}{|c|}{ Age and anthropometric variables } \\
\hline Age (years) Mean (SD) & $24.6(1.4)$ & $24.7(1.5)$ \\
\hline Adult weight (kg) Median (IQR) & 70.1 (63.0 to 77.9$)$ & 61.5 (54.9 to 70.0$)$ \\
\hline Adult height (cm) Mean (SD) & $168.1(6.1)$ & $156.3(5.5)$ \\
\hline BMI (kg/m²) Median (IQR) & 24.7 (22.6 to 27.2$)$ & 25.1 (22.6 to 28.6$)$ \\
\hline Weight at birth (g) Mean (SD) & $3184(488.2)$ & $3192(508.0)$ \\
\hline \multicolumn{3}{|c|}{ Measurements of lung function (Mean (SD)) } \\
\hline $\mathrm{FEV}_{1}(\mathrm{~L})^{\dagger}$ & $4.12(0.53)$ & $3.09(0.38)$ \\
\hline $\begin{array}{l}\mathrm{FEV}_{1} \text { as \% of predicted value for age, } \\
\text { height and sex }\end{array}$ & $105.2(10.91)$ & $105.3(10.69)$ \\
\hline FVC $(\mathrm{L})$ & $4.78(0.63)$ & $3.53(0.44)$ \\
\hline $\begin{array}{l}\text { FVC as \% of predicted value for age, } \\
\text { height and sex }\end{array}$ & $104.9(7.3)$ & $103.2(8.5)$ \\
\hline $\mathrm{FEV}_{1} / \mathrm{FVC}$ & $0.86(0.047)$ & $0.88(0.048)$ \\
\hline Bronchial hyper-responsiveness (BHR) & & \\
\hline $\begin{array}{l}\text { as positive response to methacholine } \\
\text { challenge }(16 \mathrm{mg} / \mathrm{mL}) \%\end{array}$ & 6.3 & 15.5 \\
\hline Wheeze in the last 12 months (\%) & 26.3 & 28.4 \\
\hline Ever had asthma (\%) & 3.1 & 5.9 \\
\hline Dr diagnosed asthma (\%) & 2.6 & 5.4 \\
\hline 12 years of full time education (\%) & 50.0 & 50.0 \\
\hline \multicolumn{3}{|c|}{ Number of household belongings (as estimation of SES) $(N(\%))$} \\
\hline 0 or 1 & $75(13.8)$ & $93(14.3)$ \\
\hline 2 & $164(30.2)$ & $223(34.4)$ \\
\hline 3 & $173(31.9)$ & $211(32.5)$ \\
\hline 4 or 5 & $131(24.1)$ & $122(18.8)$ \\
\hline
\end{tabular}

${ }^{\dagger}$ Highest of five measurements. 
Table 2. Daily average dietary intake of foods and antioxidants.

\begin{tabular}{|c|c|c|c|c|c|c|c|c|}
\hline \multirow{2}{*}{ Energy and Nutrients } & \multirow{2}{*}{$\begin{array}{c}\text { Males } \\
\text { Median [IQR] }\end{array}$} & \multirow{2}{*}{$\%$ TEI } & \multirow{2}{*}{$\%$ EAR } & \multirow{2}{*}{$\%$ RNI } & \multirow{2}{*}{$\begin{array}{c}\text { Females } \\
\text { Median [IQR] }\end{array}$} & \multirow{2}{*}{$\%$ TEI } & \multirow{2}{*}{$\%$ EAR } & \multirow{2}{*}{$\% \mathrm{RN}$} \\
\hline & & & & & & & & \\
\hline Total Fruits (g) & $182.5[92.0-210.8]$ & & & & $175.3[87.4-205.2]$ & & & \\
\hline Total vegetables $(\mathrm{g})$ & 432.4 [390.8-462.0] & & & & 345.2 [294.8-401.6] & & & \\
\hline Total energy intake (TEI) (kcal) & 3439 [2665.0-4415.0] & & 134.9 & & 2279 [1170.0-2844.0] & & 117.5 & \\
\hline Proteins (g) & 129.6 [98.4-163.3] & 18.2 & 292 & & $92.1[71.0-118.1]$ & 15.4 & 256 & \\
\hline Carbohydrates (g) & 502.6 [385.1-625.2] & 58.5 & 136.0 & & 328.8 [254.4-427.8] & 57.7 & 138.0 & \\
\hline Total lipids (g) & $97.9[71.1-137.6]$ & 23.3 & 73.1 & & 66.1 [48.2-91.9] & 26.9 & 74.6 & \\
\hline PUFA (g) & $26.2[18.3-36.1]$ & 6.9 & 106.2 & & $18.7[13.3-25.5]$ & 7.4 & 113.8 & \\
\hline MUFA (g) & $36.6[25.5-55.1]$ & 9.6 & 73.8 & & $23.3[16.7-35.5]$ & 9.2 & 70.8 & \\
\hline SFA (g) & $26.1[18.9-38.1]$ & 6.8 & 61.8 & & $17.1[11.7-25.1]$ & 6.8 & 61.8 & \\
\hline Omega 3 (g) & $0.24[0.1-0.5]$ & 0.06 & 1.2 & & $0.2[0.1-0.4]$ & 0.08 & 4.0 & \\
\hline Omega 6 (g) & $11.9[7.7-17.0]$ & 3.1 & 310 & & $8.5[5.8-13.1]$ & 3.4 & 340 & \\
\hline Carotene $(\mu \mathrm{g})$ & $1027.0[585.6-1707.0]$ & & & 98 & 1107.1 [681.2-1876.8] & & & 96 \\
\hline Total vitamin A $(\mu \mathrm{g})$ & $1412.3[854.4-2121.7]$ & & & 155 & 1374.5 [891.7-2328.9] & & & 250 \\
\hline Vitamin C (mg) & 133.3 [84.9-235.1] & & & 221 & 138.7 [81.7-229.2] & & & 230 \\
\hline Vitamin E (mg) & 19.6 [14.2-26.3] & & & 131 & 15.2 [10.9-19.7] & & & 100 \\
\hline Selenium $(\mu \mathrm{g})$ & 163.8 [119.9-203.2] & & & 82 & 100.6 [77.5-129.7] & & & 50 \\
\hline Zinc (mg) & 11.8 [9.2-14.7] & & & 100 & 9.5 [7.2-10.9] & & & 119 \\
\hline Total catechins (mg) & $17.1[7.8-64.4]$ & & & NA & 21.2 [9.3-68.5] & & & NA \\
\hline Flavonols (mg) & 26.2 [15.7-44.3] & & & NA & 24.7 [12.7-41.3] & & & NA \\
\hline Flavones (mg) & $0.1[0.04-0.2]$ & & & NA & $0.1[0.03-0.2]$ & & & $\mathrm{NA}$ \\
\hline
\end{tabular}

\% TEI: The percentage of total energy intake; \% EAR: the percentage of estimated average recommendation per day; \% RNI: percentage of recommended nutritional intake; NA: not applicable. 
Table 3. The association between components of ventilatory function and estimated daily nutrient and antioxidant intake *.

\begin{tabular}{|c|c|c|c|c|}
\hline \multirow{2}{*}{ Nutrient } & \multirow{2}{*}{ Quintiles } & FEV $_{1}(\mathbf{L})$ & FVC (L) & FEV1/FVC \\
\hline & & \multicolumn{3}{|c|}{ Difference of Means (95\% CI) } \\
\hline \multirow{6}{*}{ Vitamin C (mg) } & 1 & 0 & 0 & 0 \\
\hline & 2 & $-0.05(-0.12$ to 0.01$)$ & $-0.10(-0.14$ to 0.014$)$ & $-0.0002(-0.01$ to 0.01$)$ \\
\hline & 3 & $-0.002(-0.07$ to 0.07$)$ & $0.04(-0.04$ to 0.12$)$ & $-0.01(-0.02$ to -0.0005$)$ \\
\hline & 4 & $0.004(-0.06$ to 0.07$)$ & $0.02(-0.10$ to 0.10$)$ & $-0.002(-0.01$ to 0.007$)$ \\
\hline & 5 & $-0.02(-0.09$ to 0.06$)$ & $-0.01(-0.09$ to 0.07$)$ & $-0.003(-0.01$ to 0.007$)$ \\
\hline & $p$ for trend & 0.75 & 0.47 & 0.44 \\
\hline \multirow{6}{*}{ Vitamin E (mg) } & 1 & 0 & 0 & 0 \\
\hline & 2 & $-0.06(-0.13$ to 0.01$)$ & $-0.07(-0.15$ to 0.01$)$ & $0.002(-0.006$ to 0.01$)$ \\
\hline & 3 & $-0.004(-0.08$ to 0.07$)$ & $0.02(-0.06$ to 0.10$)$ & $-0.004(-0.01$ to 0.005$)$ \\
\hline & 4 & $-0.02(-0.09$ to 0.06$)$ & $-0.01(-0.10$ to 0.07$)$ & $-0.0002(-0.01$ to 0.01$)$ \\
\hline & 5 & $0.01(-0.08$ to 0.09$)$ & $0.04(-0.05$ to 0.14$)$ & $-0.01(-0.02$ to 0.01$)$ \\
\hline & $p$ for trend & 0.61 & 0.23 & 0.32 \\
\hline \multirow{6}{*}{ Total vitamin A ( $\mu \mathrm{g})$} & 1 & 0 & 0 & 0 \\
\hline & 2 & $0.06(-0.004$ to 0.13$)$ & $0.05(-0.03$ to 0.13$)$ & $0.006(-0.003$ to 0.015$)$ \\
\hline & 3 & $0.04(-0.03$ to 0.11$)$ & $0.06(-0.02$ to 0.14$)$ & $-0.004(-0.013$ to 0.004$)$ \\
\hline & 4 & $0.01(-0.06$ to 0.08$)$ & $0.04(-0.04$ to 0.11$)$ & $-0.004(-0.013$ to 0.005$)$ \\
\hline & 5 & $0.02(-0.06$ to 0.09$)$ & $0.03(-0.05$ to 0.11$)$ & -0.001 ( -0.01 to 0.008$)$ \\
\hline & $p$ for trend & 0.78 & 0.65 & 0.19 \\
\hline \multirow{6}{*}{ Selenium $(\mu g)$} & 1 & 0 & 0 & 0 \\
\hline & 2 & $-0.01(-0.08$ to 0.06$)$ & $0.01(-0.07$ to 0.09$)$ & $-0.003(-0.01$ to 0.01$)$ \\
\hline & 3 & $-0.04(-0.11$ to 0.03$)$ & $-0.04(-0.12$ to 0.05$)$ & -0.001 ( -0.01 to 0.01$)$ \\
\hline & 4 & $-0.06(-0.14$ to 0.03$)$ & $-0.02(-0.012$ to 0.07 & -0.01 ( -0.02 to 0.003$)$ \\
\hline & 5 & $-0.02(-0.13$ to 0.09$)$ & 0.06 (-0.06 to 0.18$)$ & $-0.01(-0.03$ to 0.0001$)$ \\
\hline & $p$ for trend & 0.30 & 0.90 & 0.09 \\
\hline \multirow{6}{*}{ Zinc (mg) } & 1 & 0 & 0 & 0 \\
\hline & 2 & $0.02(-0.05$ to 0.09$)$ & -0.001 ( -0.08 to 0.08$)$ & $0.01(-0.003$ to 0.01$)$ \\
\hline & 3 & $-0.05(-0.12$ to 0.03$)$ & $-0.04(-0.12$ to 0.04$)$ & $-0.002(-0.01$ to 0.01$)$ \\
\hline & 4 & $-0.01(-0.09$ to 0.07$)$ & $0.05(-0.09$ to 0.13$)$ & $-0.01(-0.02$ to 0.0001$)$ \\
\hline & 5 & $0.01(-0.09$ to 0.11$)$ & $0.02(-0.09$ to 0.13$)$ & $-0.001(-0.01$ to 0.01$)$ \\
\hline & $p$ for trend & 0.82 & 0.48 & 0.14 \\
\hline \multirow{6}{*}{ Omega 3 fatty acids (mg) } & 1 & 0 & 0 & 0 \\
\hline & 2 & $0.04(-0.03$ to 0.11$)$ & $0.05(-0.02$ to 0.13$)$ & -0.003 ( -0.01 to 0.01$)$ \\
\hline & 3 & $0.05(-0.02$ to 0.11$)$ & $0.04(-0.04$ to 0.12$)$ & $0.002(-0.001$ to 0.01$)$ \\
\hline & 4 & $0.08(0.01$ to 0.14$)$ & $0.08(0.003$ to 0.16$)$ & $0.002(-0.01$ to 0.01$)$ \\
\hline & 5 & $0.08(0.005$ to 0.15$)$ & $0.08(0.001$ to 0.16$)$ & $0.001(-0.01$ to 0.01$)$ \\
\hline & $p$ for trend & 0.02 & 0.04 & 0.52 \\
\hline \multirow{6}{*}{ Omega 6 fatty acids (mg) } & 1 & 0 & 0 & 0 \\
\hline & 2 & $-0.08(-0.14$ to -0.01$)$ & $-0.08(-0.15$ to 0.001$)$ & $-0.002(-0.1$ to 0.01$)$ \\
\hline & 3 & -0.03 ( -0.10 to 0.04$)$ & $-0.28(-0.11$ to 0.05$)$ & $-0.003(-0.01$ to 0.01$)$ \\
\hline & 4 & $-0.01(-0.08$ to 0.10$)$ & -0.001 ( -0.08 to 0.08$)$ & $-0.002(-0.01$ to 0.007$)$ \\
\hline & 5 & -0.005 ( -0.08 to 0.07$)$ & $0.01(-0.07$ to 0.09$)$ & $-0.002(-0.01$ to 0.007$)$ \\
\hline & $p$ for trend & 0.51 & 0.41 & 0.73 \\
\hline
\end{tabular}


Table 3. Cont.

\begin{tabular}{|c|c|c|c|c|}
\hline \multirow{2}{*}{ Nutrient } & \multirow{2}{*}{ Quintiles } & $\operatorname{FEV}_{1}(\mathrm{~L})$ & FVC (L) & FEV $_{1} /$ FVC \\
\hline & & \multicolumn{3}{|c|}{ Difference of Means (95\% CI) } \\
\hline \multirow{6}{*}{ Flavones (mg) } & 1 & 0 & 0 & 0 \\
\hline & 2 & $0.01(-0.05$ to 0.08$)$ & 0.01 ( -0.06 to 0.09$)$ & -0.001 ( -0.01 to 0.01$)$ \\
\hline & 3 & $0.02(-0.05$ to 0.09$)$ & 0.004 ( -0.07 to 0.08$)$ & 0.002 ( -0.01 to 0.01$)$ \\
\hline & 4 & $-0.002(-0.07$ to 0.07$)$ & 0.003 ( -0.07 to 0.08$)$ & -0.002 ( -0.01 to 0.01$)$ \\
\hline & 5 & $0.01(-0.06$ to 0.07$)$ & $0.01(-0.06$ to 0.09$)$ & -0.001 ( -0.01 to 0.01$)$ \\
\hline & p per trend & 0.96 & 0.85 & 0.77 \\
\hline \multirow{6}{*}{ Flavonols (mg) } & 1 & 0 & 0 & \\
\hline & 2 & 0.07 (0.003 to 0.14$)$ & 0.09 (0.01 to 0.16$)$ & 0.001 ( -0.01 to 0.01$)$ \\
\hline & 3 & $0.05(-0.02$ to 0.12$)$ & $0.06(-0.01$ to 0.14$)$ & -0.001 ( -0.01 to 0.01$)$ \\
\hline & 4 & $0.05(-0.02$ to 0.12$)$ & $0.07(-0.004$ to 0.15$)$ & -0.002 ( -0.01 to 0.01$)$ \\
\hline & 5 & 0.08 (0.01 to 0.16$)$ & 0.10 (0.02 to 0.18$)$ & 0.002 ( -0.01 to 0.01$)$ \\
\hline & $p$ for trend & 0.08 & 0.05 & 0.99 \\
\hline \multirow{6}{*}{ Total catechins (mg) } & 1 & 0 & 0 & 0 \\
\hline & 2 & -0.04 ( -0.11 to 0.03$)$ & -0.04 ( -0.13 to 0.03$)$ & 0.0003 ( -0.01 to 0.01$)$ \\
\hline & 3 & $0.03(-0.03$ to 0.11$)$ & $0.06(-0.02$ to 0.13$)$ & $-0.01(-0.02$ to 0.003$)$ \\
\hline & 4 & $0.04(-0.03$ to 0.11$)$ & 0.08 (0.003 to 0.16$)$ & -0.01 ( -0.02 to 0.002$)$ \\
\hline & 5 & 0.04 ( -0.03 to 0.11$)$ & 0.07 (0.01 to 0.15$)$ & -0.01 ( -0.01 to 0.004$)$ \\
\hline & $p$ for trend & 0.06 & 0.006 & 0.09 \\
\hline
\end{tabular}

* Multiple linear regression adjusted by age, sex, height, house crowding, educational level, current smoking status, socioeconomic level, birth weight, BMI and TEI.

Table 4. The association between ventilatory function and estimated daily intake of fruits and vegetables rich in antioxidants *.

\begin{tabular}{|c|c|c|c|c|}
\hline \multirow{2}{*}{ Food Group } & \multirow{2}{*}{ Quintiles } & $\operatorname{FEV}_{1}(\mathrm{~L})$ & FVC (L) & $\mathrm{FEV}_{1} / \mathrm{FVC}$ \\
\hline & & \multicolumn{3}{|c|}{ Difference of Means (95\% CI) } \\
\hline \multirow{6}{*}{ Total fruits (g) } & 1 & 0 & & 0 \\
\hline & 2 & $-0.02(-0.09$ to 0.05$)$ & $-0.01(-0.09$ to 0.06$)$ & $-0.004(-0.01$ to 0.01$)$ \\
\hline & 3 & $0.03(-0.04$ to 0.10$)$ & 0.04 (-0.04 to 0.11$)$ & $-0.002(-0.01$ to 0.004$)$ \\
\hline & 4 & $0.02(-0.05$ to 0.09$)$ & 0.05 ( -0.03 to 0.12$)$ & $-0.005(-0.01$ to 0.004$)$ \\
\hline & 5 & 0.05 (-0.02 to 0.12$)$ & 0.08 (0.003 to 0.15$)$ & $-0.005(-0.01$ to 0.003$)$ \\
\hline & $p$ for trend & 0.09 & 0.02 & 0.23 \\
\hline \multirow{6}{*}{ Total vegetables (g) } & 1 & 0 & 0 & 0 \\
\hline & 2 & $0.03(-0.04$ to 0.10$)$ & $0.02(-0.06$ to 0.09$)$ & 0.004 (-0.01 to 0.01$)$ \\
\hline & 3 & 0.01 ( -0.06 to 0.08$)$ & 0.05 ( -0.03 to 0.13$)$ & $-0.01(-0.02$ to 0.002$)$ \\
\hline & 4 & 0.01 ( -0.06 to 0.08$)$ & 0.05 ( -0.03 to 0.13$)$ & $-0.01(-0.02$ to 0.0002$)$ \\
\hline & 5 & $0.03(-0.05$ to 0.10$)$ & 0.05 ( -0.04 to 0.13$)$ & $-0.002(-0.01$ to 0.007$)$ \\
\hline & $p$ for trend & 0.74 & 0.17 & 0.10 \\
\hline
\end{tabular}

* Multiple linear regression adjusted by age, sex, height, house crowding, educational level, current smoking status, socioeconomic level, birth weight, body mass index, and TEI.

PCA identified two patterns in these adults, which explained $24.7 \%$ of the variance in the original 65 food items (Figure A1 in Appendix). One dietary pattern was highly correlated with animal proteins 
and starchy food, and the second was characterised by fruits and vegetables (data not shown but available from the authors). The logistic regressions between each pattern and the three respiratory outcomes showed no association (Table 5).

Table 5. Association between quintiles of dietary patterns and ventilatory capacity *.

\begin{tabular}{|c|c|c|c|}
\hline Lung Function & Quintiles of Dietary Patterns & $\begin{array}{c}\text { Unadjusted Odds Ratio } \\
\text { (SE) }\end{array}$ & $\begin{array}{c}\text { Adjusted Odds Ratio } \\
\text { (SE) }\end{array}$ \\
\hline \multirow{14}{*}{$\mathrm{FEV}_{1}$} & "Animal proteins and starchy food & & \\
\hline & 1 & 0 & 0 \\
\hline & 2 & $0.10(0.06)$ & $-0.05(0.04)$ \\
\hline & 3 & $0.30(0.06)$ & $-0.02(0.04)$ \\
\hline & 4 & $0.62(0.06)$ & $-0.01(0.04)$ \\
\hline & 5 & $0.75(0.05)$ & $-0.04(0.05)$ \\
\hline & $p$ for trend & $<0.0001$ & 0.78 \\
\hline & "Fruits and vegetables" & & \\
\hline & 1 & 0 & 0 \\
\hline & 2 & $-0.0001(0.06)$ & $0.03(0.04)$ \\
\hline & 3 & $-0.12(0.06)$ & $-0.03(0.04)$ \\
\hline & 4 & $-0.04(0.06)$ & $0.03(0.04)$ \\
\hline & 5 & $-0.09(0.01)$ & $0.03(0.04)$ \\
\hline & $p$ for trend & 0.11 & 0.48 \\
\hline \multirow{14}{*}{ FVC } & "Animal proteins and starchy food & & \\
\hline & 1 & 0 & 0 \\
\hline & 2 & $0.14(0.07)$ & $-0.05(0.04)$ \\
\hline & 3 & $0.37(0.07)$ & $-0.008(0.04)$ \\
\hline & 4 & $0.79(0.07)$ & $0.01(0.05)$ \\
\hline & 5 & $0.94(0.07)$ & $-0.03(0.06)$ \\
\hline & $p$ for trend & $<0.0001$ & 0.93 \\
\hline & "Fruits and vegetables” & & \\
\hline & 1 & 0 & 0 \\
\hline & 2 & $-0.008(0.07)$ & $0.03(0.04)$ \\
\hline & 3 & $-0.12(0.07)$ & $-0.008(0.85)$ \\
\hline & 4 & $-0.01(0.07)$ & $0.07(0.04)$ \\
\hline & 5 & $-0.10(0.07)$ & $0.05(0.04)$ \\
\hline & $p$ for trend & 0.21 & 0.14 \\
\hline \multirow{7}{*}{$\mathrm{FEV}_{1} / \mathrm{FVC}$} & "Animal proteins and starchy food & & \\
\hline & 1 & 0 & 0 \\
\hline & 2 & $-0.05(0.004)$ & $-0.003(0.004)$ \\
\hline & 3 & $-0.008(0.004)$ & $-0.003(0.005)$ \\
\hline & 4 & $-0.02(0.004)$ & $-0.005(0.005)$ \\
\hline & 5 & $-0.02(0.005)$ & $-0.002(0.007)$ \\
\hline & $p$ for trend & $<0.0001$ & 0.54 \\
\hline
\end{tabular}


Table 5. Cont.

\begin{tabular}{cccc}
\hline Lung Function & Quintiles of Dietary Patterns & $\begin{array}{c}\text { Unadjusted Odds Ratio } \\
\text { (SE) }\end{array}$ & $\begin{array}{c}\text { Adjusted Odds Ratio } \\
\text { (SE) }\end{array}$ \\
\hline "Fruits and vegetables" & & 0 \\
Ratio FEV 1 FVC & 1 & 0 & $0.002(0.004)$ \\
& 2 & $0.003(0.004)$ & $-0.004(0.004)$ \\
& 3 & $-0.002(0.004)$ & $-0.006(0.005)$ \\
& 5 & $-0.005(0.005)$ & $-0.001(0.005)$ \\
\hline
\end{tabular}

* Multiple linear regression adjusted by age, sex, height, house crowding, educational level, current smoking status, socioeconomic level, birth weight, BMI, and TEI.

\section{Discussion}

In this population-based study of young adults, we have found that a better FVC was positively associated with a higher intake of total catechins and of fresh fruits. There was also a positive association between ventilatory function and omega 3 fatty acids but it lost statistical significance after adjustment for multiple comparisons.

Nutrient estimates were obtained from the Chilean Food Composition Table, as an attempt to ascertain local nutrient composition data. Although we used a software based on values from the USDA Food Composition Table, we also used nutrient data calculated from Chilean foods, particularly on fresh vegetables and fruits. Most studies in developing countries rely on larger nutrient datasets from the USA or the UK. We found that level of agreement between the Chilean and British Food Composition Tables were very high [19].

Studies on the relationship between ventilatory function and dietary exposures in Latin American adults (or children) are still lacking. This is a public health challenge as the burden of COPD in these countries appears to be similar to that observed in developed countries [23], and yet, the evidence on environmental risk factors is scant. Observational studies from countries with more advanced economies support our findings of a positive association between lung function and intake of fresh fruit. Strachan et al. [10] suggested in the early 90s that a lower intake of fresh fruit was related to a lower lung function (estimated as $\mathrm{FEV}_{1}$ ) in adults, with the effect being observed in both smokers and life-long non-smokers. In a random sample from Scottish adults, Kelly and colleagues [7] found that a higher intake of fresh fruits was related to a higher $\mathrm{FEV}_{1}$. A recent case-control study showed that FEV 1 was statistically significantly lower as the dietary inflammatory index (DII) increased. A higher DII is a reflection of a reduced intake of fresh fruit and vegetables [24].

Prospective studies in adults investigating how fruit intake might be related to lung function show that such an effect would appear to be more evident with changes in consumption of fruits rather than with a regular intake sustained in time [9]. In a seven year follow-up of British adults, Carey and colleagues [9] reported that a reduction in fruit intake was related to a more significant decline of lung function, measured as $\mathrm{FEV}_{1}$. A more recent prospective study found that a higher intake of fresh fruit and some of the antioxidants commonly found in these foods would favour a slower decline in lung function (measured as $\mathrm{FEV}_{1}$ ) in adults, the effect being considerable higher in smokers or 
ex-smokers [25]. Contrary to these findings, Butland and colleagues [8] showed that changes in apple intake were unrelated to $\mathrm{FEV}_{1}$ after 10 years of follow-up in adults.

In spite of the growing molecular evidence of the benefits of flavonoids on lung structure [26], epidemiological studies on the association between flavonoids and lung function is still scant. Our results of a positive association between catechins and lung function confirm those reported by Tabak and colleagues [27], who reported a $130 \mathrm{~mL}$ higher $\mathrm{FEV}_{1}$ in Dutch adults who had the highest vs. lowest intakes of catechins. Evidence from molecular studies suggests these flavonoids may have a pivotal role in the pathogenesis of COPD, and to have multiple functions including antioxidant and anti-inflammatory properties [28]. Catechins have been shown to directly stimulate the activity of the nuclear protein Sirtuin 1 (SIRT 1), which regulates a variety of physio-pathological processes in the lung epithelial cells including delaying cellular aging, resistance to oxidative stress, and anti-inflammation [29]. Improving our understanding on the regulation of flavonoid metabolism and its regulation by genes would be a step closer to understanding the mechanisms by which flavonoids are involved in poor lung function and in the aetiology of COPD.

In our study population, the estimated daily intake of fish averaged $10 \mathrm{~g}$ per day, which is $30 \%$ less than the per capita intake of $5.1 \mathrm{~kg} /$ year described for the Chilean population [30]. We found a positive association between $\mathrm{FEV}_{1}$ and omega 3 fatty acid intake. We are cautious in the interpretation of this result as after controlling multiple testing, the association was no longer significant. However other observational studies have shown that individuals with a higher intake of omega 6 fatty acids and of isoflavonoids have a reduced risk of COPD [31]. There is evidence that a higher intake of docosahexaenoic acid increases lung function in smokers, but this protective effect is not seen in heavy smokers [32]. This raises the question of whether a higher intake of food sources rich in these compounds could ameliorate or delay the development of COPD by maintaining good lung function.

The use of dietary patterns to assess the relationship between diet and disease has been found on the theoretical conception that foods are not consumed in isolation but as meals, which form a dietary pattern. This observation has prompted several epidemiological studies to look at dietary patterns and respiratory diseases. The evidence on whole diet and lung function is still emerging. McKeever et al. [33] found a statistically significant reduction in $\mathrm{FEV}_{1}$ in adults eating a "traditional" dietary pattern comprised mainly of potatoes and meat, whilst Shaheen and colleagues [11] found that a "prudent" pattern, comprised of fruit, vegetables, fish and wholemeal cereals, was associated with an improved FEV 1 in adults.

In contrast to these studies we found no association between measures of ventilatory function and dietary patterns. One possibility for the discrepancy between the PCA analyses is that the patterns of the three studies did not include the same foods, and what researchers choose to define as "prudent" or "Western”, or "traditional” or "animal proteins and starchy food” might imply different food components. It is also possible that dietary patterns from adults in South America may not align with those of European countries, as dietary habits are known to be different between these populations.

The assessment of lung function in our study followed a rigorous standardised protocol, providing reliable data on spirometric values. The response rate was high and participants were representative of the area where the research took place. Whilst FFQs are known to have measurement errors, which usually lead to overestimations of the net dietary intake, the FFQ used in this population was designed a priori to take into account the hypothesis we were testing on effect of dietary intake of antioxidants 
and poor lung function in young adults. Therefore, the list of 65 food items included was mainly concerned with foods with known antioxidant content of vitamins or flavonoids available in this region, as well as foods that are part of the usual diet of Chilean adults.

This is a cross-sectional study with limited ability to infer causality. The dietary intake was self-reported and this might lead to under- or over-reporting of actual intake. In spite of these limitations, the consistency of our findings with recent findings from prospective observational [25] and long term intervention studies [34] showing a protective effect of a higher intake of fresh fruits on adult lung function, would lend support to a possible causal interpretation. We believe that the weak association reported between vegetable intake, omega 3 fatty acids, and lung function outcomes deserves further exploration. We have erred in the side of caution in the analysis because the FFQ has a margin of measurement error and our adjustment for several potential confounders and for multiple comparisons, greatly reduced the chance to find significant associations.

\section{Conclusions}

To our knowledge, this is the first epidemiological study to investigate the association between dietary antioxidants and ventilatory function in adults from Latin America. Our findings suggest that intake of fresh fruits and catechins would contribute to the preservation of lung function in adults and possibly reduce the risk of chronic respiratory diseases later in life.

\section{Acknowledgments}

This study was funded by a grant from The Wellcome Trust (Grant No. 059448Z7). The authors are indebted to the nurses for their dedication in collecting the data and to the people from Limache and Olmue who helped us to investigate their health and diet.

\section{Author Contributions}

Vanessa Garcia-Larsen proposed and carried out the analyses, and wrote the manuscript. Roberto J. Rona is the Principal Investigator (PI) who was awarded the funding from the Wellcome Trust that made possible to carry out this study. Roberto J. Rona gave direction and feedback to the data analysis, the interpretation of results and to the discussion. Hugo Amigo and Patricia Bustos led the scientific research team that carried out the field work of the study. Hugo Amigo and Patricia Bustos contributed with the writing and interpretation of the results. Ioannis Bakolis contributed with the data analysis and interpretation of the results. All authors contributed towards the final version of the manuscript. 


\section{Appendix}

Table A1. Empirically Derived Dietary Patterns. Correlations between food items and dietary patterns (only correlations $>0.3$ or $<-0.3$ are included).

\begin{tabular}{|c|c|c|}
\hline Food Item & Dietary Pattern I (Western Diet) & Dietary Pattern II (Fruit and Vegetables) \\
\hline Orange & 0 & 0 \\
\hline Lemon & 0 & 0.3199218 \\
\hline Kiwi & 0 & 0 \\
\hline Apple & 0 & 0.3203267 \\
\hline Strawberrie & 0 & 0 \\
\hline Mandarin & 0 & 0 \\
\hline Beetroot & 0 & 0.4113356 \\
\hline Chard & 0 & 0.3344303 \\
\hline Sweetpepper & 0 & 0.3768218 \\
\hline Garlic & 0 & 0.3903755 \\
\hline Onion & 0 & 0.4760728 \\
\hline Tomato & 0 & 0.3935958 \\
\hline Potato & 0.6293718 & 0.3563259 \\
\hline Pumpkin & 0 & 0.5209844 \\
\hline Carrot & 0 & 0.4572368 \\
\hline Avocado & 0.3387931 & 0 \\
\hline Bean & 0 & 0.3883224 \\
\hline Lentil & 0 & 0.3531107 \\
\hline Chickpeas & 0 & 0 \\
\hline Meataverage & 0 & 0 \\
\hline Meatnofat & 0 & 0 \\
\hline Meatfat & 0.3405617 & 0 \\
\hline Chickenav & 0 & 0 \\
\hline Chickskin & 0 & 0 \\
\hline Chicknoskin & 0 & 0 \\
\hline Ribs & 0.4815942 & 0 \\
\hline Salmon & 0 & 0 \\
\hline Fish & 0 & 0 \\
\hline Shellfish & 0 & 0 \\
\hline Eggs & 0.3899055 & 0 \\
\hline Bread & 0.426953 & 0 \\
\hline Brownbread & 0 & 0 \\
\hline Knybread & 0 & 0 \\
\hline Pasta & 0.4377254 & 0 \\
\hline Rice & 0.3212484 & 0 \\
\hline Cake & 0 & 0 \\
\hline Oil & 0.400673 & 0 \\
\hline Bacon & 0 & 0 \\
\hline Sausage1 & 0.3344502 & 0 \\
\hline Frankfurter & 0.4175243 & 0 \\
\hline Ham & 0.5813709 & 0 \\
\hline
\end{tabular}


Table A1. Cont.

\begin{tabular}{ccc}
\hline Food Item & Dietary Pattern I (Western Diet) & Dietary Pattern II (Fruit and Vegetables) \\
\hline Offal & 0 & 0 \\
Margarine & 0 & 0 \\
Butter & 0 & 0 \\
Marbutter & 0 & 0 \\
Marglight & 0 & 0 \\
Mayonaise & 0.4619392 & 0 \\
Maylight & 0 & 0 \\
Wholemilk & 0 & 0 \\
Sskmilk & 0 & 0 \\
Smilk & 0 & 0 \\
Yoghurt & 0 & 0 \\
Cheeseg & 0.5296596 & 0 \\
Maturecheese & 0 & 0 \\
Cottagecheese & 0 & 0 \\
Sugar & 0 & 0 \\
Jam & 0 & 0 \\
Honey & 0 & 0 \\
Coke & 0.3835198 & 0 \\
Juice & 0 & 0 \\
Tealight & 0 & 0 \\
Teadark & 0 & 0 \\
Coffee & 0.3425927 & 0 \\
Redwine & 0 & 0 \\
Salt & & 0 \\
\hline
\end{tabular}

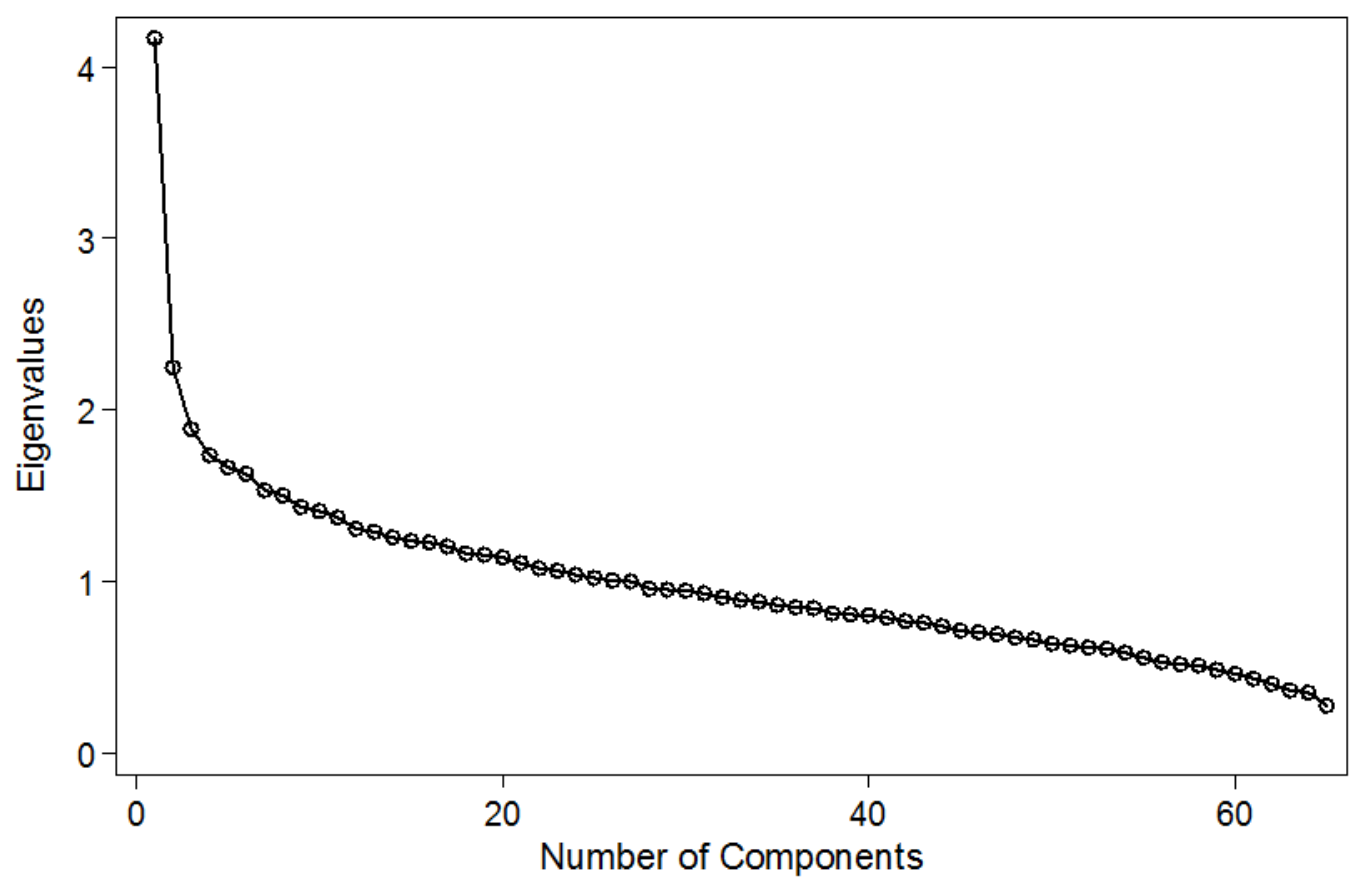

Figure A1. Scree plot of PCA for dietary patterns derived. 


\section{Conflicts of Interest}

The authors declare no conflict of interest.

\section{References}

1. James, A.L.; Palmer, L.J.; Kicic, E.; Maxwell, P.S.; Lagan, S.E.; Ryan, G.F.; Musk, A.W. Decline in lung function in the Busselton Health Study: The effects of asthma and cigarette smoking. Am. J. Respir. Crit. Care Med. 2005, 171, 109-114.

2. Young, R.P.; Hopkins, R.; Eaton, T.E. Forced expiratory volume in one second: Not just a lung function test but a marker of premature death from all causes. Eur. Respir. J. 2007, 30, 616-622.

3. Tockman, M.S.; Pearson, J.D.; Fleg, J.L.; Metter, E.J.; Kao, S.Y.; Rampal, K.G.; Cruise, L.J.; Fozard, J.L. Rapid decline in FEV1. A new risk factor for coronary heart disease mortality. Am. J. Respir. Crit. Care Med. 1995, 151, 390-398.

4. Schroeder, E.B.; Welch, V.L.; Couper, D.; Nieto, F.J.; Liao, D.; Rosamond, W.D.; Heiss, G. Lung function and incident coronary heart disease: The Atherosclerosis Risk in Communities Study. Am. J. Epidemiol. 2003, 158, 1171-1181.

5. Mannino, D.M.; Buist, A.S. Global burden of COPD: Risk factors, prevalence, and future trends. Lancet 2007, 370, 765-773.

6. Tabak, C.; Smit, H.A.; Rasanen, L.; Fidanza, F.; Menotti, A.; Nissinen, A.; Feskens, E.J.; Heederik, D.; Kromhout, D. Dietary factors and pulmonary function: A cross sectional study in middle aged men from three European countries. Thorax 1999, 54, 1021-1026.

7. Kelly, Y.; Sacker, A.; Marmot, M. Nutrition and respiratory health in adults: Findings from the health survey for Scotland. Eur. Respir. J. 2003, 21, 664-671.

8. Butland, B.K.; Strachan, D.P.; Anderson, H.R. Fresh fruit intake and asthma symptoms in young British adults: Confounding or effect modification by smoking? Eur. Respir. J. 1999, 13, 744-750.

9. Carey, I.M.; Strachan, D.P.; Cook, D.G. Effects of changes in fresh fruit consumption on ventilatory function in healthy British adults. Am. J. Respir. Crit. Care Med. 1998, 158, 728-733.

10. Strachan, D.P.; Cox, B.D.; Erzinclioglu, S.W.; Walters, D.E.; Whichelow, M.J. Ventilatory function and winter fresh fruit consumption in a random sample of British adults. Thorax 1991, 46, 624-629.

11. Shaheen, S.O.; Jameson, K.A.; Syddall, H.E.; Aihie-Sayer, A.; Dennison, E.M.; Cooper, C.; Robinson, S.M.; Hertfordshire Cohort Study Group. The relationship of dietary patterns with adult lung function and COPD. Eur. Respir. J. 2010, 36, 277-284.

12. De Oca, M.M.; Tálamo, C.; Halbert, R.J.; Perez-Padilla, R.; Lopez, M.V.; Muiño, A.; Jardim, J.R.; Valdivia, G.; Pertuzé, J.; Moreno, D.; et al. Frequency of self-reported COPD exacerbation and airflow obstruction in five Latin American cities: The Proyecto Latinoamericano de Investigacion en Obstruccion Pulmonar (PLATINO) study. Chest 2009, 136, 71-78.

13. Amigo, H.; Bustos, P.; Zumelzu, E.; Rona, R.J. Cohort Profile: The Limache, Chile, birth cohort study. Int. J. Epidemiol. 2014, 43, 1031-1039.

14. Oyarzun, M. Normal spirometric values in the Chilean population. Rev. Med. Chile 1996, 124, 1365-1367. 
15. Knudson, R.J.; Lebowitz, M.D.; Holberg, C.J.; Burrows, B. Changes in the normal maximal expiratory flow-volume curve with growth and aging. Am. Rev. Respir. Dis. 1983, 127, 725-734.

16. American Thoracic Society. Standardization of spirometry, 1994 update. Am. J. Respir. Crit. Care Med. 1995, 152, 1107-1136.

17. Chilean Ministry of Health. Dietary Guidelines for Chile; Ministry of Health: Santiago, Chile, 1996.

18. Pinheiro, A.C.; Fuentes, L.A. Sofnut (Software for Dietary Intake Analysis); Sofmatica, Ltd.: Santiago, Chile, 2002.

19. Garcia, V.; Rona, R.J.; Chinn, S. Effect of the choice of food composition table on nutrient estimates: A comparison between the British and American (Chilean) tables. Public Health Nutr. 2004, 7, 577-583.

20. Arts, I.C.; van de Putte, B.; Hollman, P.C. Catechin contents of foods commonly consumed in The Netherlands. 1. Fruits, vegetables, staple foods, and processed foods. J. Agric. Food Chem. 2000, 48, 1746-1751.

21. Corvalan, C.; Amigo, H.; Bustos, P.; Rona, R.J. Socioeconomic risk factors for asthma in Chilean young adults. Am. J. Public Health 2005, 95, 1375-1381.

22. Simes, R.J. An improved Bonferroni procedure for multiple tests of significance. Biometrika 1986, 73, 751-754.

23. Menezes, A.M.; Muiño, A.; López-Varela, M.V.; Valdivia, G.; Lisboa, C.; Jardim, J.R.; Montes de Oca, M.; Tálamo, C.; Wehrmeister, F.C.; Perez-Padilla, R.; et al. A population-based cohort study on chronic obstructive pulmonary disease in Latin America: Methods and preliminary results. The PLATINO Study Phase II. Arch. Bronconeumol. 2014, 50, 10-17.

24. Wood, L.G.; Shivappa, N.; Berthon, B.S.; Gibson, P.G.; Hebert, J.R. Dietary inflammatory index is related to asthma risk, lung function and systemic inflammation in asthma. Clin. Exp. Allergy 2015, 45, 177-183, doi:10.1111/cea.12323.

25. Bentley, A.R.; Kritchevsky, S.B.; Harris, T.B.; Holvoet, P.; Jensen, R.L.; Newman, A.B.; Lee, J.S.; Yende, S.; Bauer, D.; Cassano, P.A.; et al. Dietary antioxidants and forced expiratory volume in $1 \mathrm{~s}$ decline: The Health, Aging and Body Composition study. Eur. Respir. J. 2012, 39, 979-984.

26. Lago, J.H.; Toledo-Arruda, A.C.; Mernak, M.; Barrosa, K.H.; Martins, M.A.; Tibério, I.F.; Prado, C.M. Structure-activity association of flavonoids in lung diseases. Molecules 2014, 19, 3570-3595.

27. Tabak, C.; Arts, I.C.; Smit, H.A.; Heederik, D.; Kromhout, D. Chronic obstructive pulmonary disease and intake of catechins, flavonols, and flavones: The MORGEN Study. Am. J. Respir. Crit. Care Med. 2001, 164, 61-64.

28. Chung, S.; Yao, H.; Caito, S.; Hwang, J.W.; Arunachalam, G.; Rahman, I. Regulation of SIRT1 in cellular functions: Role of polyphenols. Arch. Biochem. Biophys. 2010, 501, 79-90.

29. Caito, S.; Rajendrasozhan, S.; Cook, S.; Chung, S.; Yao, H.; Friedman, A.E.; Brookes, P.S.; Rahman, I. SIRT1 is a redox-sensitive deacetylase that is post-translationally modified by oxidants and carbonyl stress. FASEB J. 2010, 24, 3145-3159.

30. Rozowski, J.; Castillo, O. Is the Chilean diet a Mediterranean-type diet? Biol. Res. 2004, 37, 313-319. 
31. Hirayama, F.; Lee, A.H.; Binns, C.W.; Hiramatsu, N.; Mori, M.; Nishimura, K. Dietary intake of isoflavones and polyunsaturated fatty acids associated with lung function, breathlessness and the prevalence of chronic obstructive pulmonary disease: Possible protective effect of traditional Japanese diet. Mol. Nutr. Food Res. 2010, 54, 909-917.

32. Sharp, D.S.; Rodriguez, B.L.; Shahar, E.; Hwang, L.J.; Burchfiel, C.M. Fish consumption may limit the damage of smoking on the lung. Am. J. Respir. Crit. Care Med. 1994, 150, 983-987.

33. McKeever, T.M.; Lewis, S.A.; Cassano, P.A.; Ocké, M.; Burney, P.; Britton, J.; Smit, H.A. Patterns of dietary intake and relation to respiratory disease, forced expiratory volume in $1 \mathrm{~s}$, and decline in 5-y forced expiratory volume. Am. J. Clin. Nutr. 2010, 92, 408-415.

34. Keranis, E.; Makris, D.; Rodopoulou, P.; Martinou, H.; Papamakarios, G.; Daniil, Z.; Zintzaras, E.; Gourgoulianis, K.I. Impact of dietary shift to higher-antioxidant foods in COPD: A randomised trial. Eur. Respir. J. 2010, 36, 774-780.

(C) 2015 by the authors; licensee MDPI, Basel, Switzerland. This article is an open access article distributed under the terms and conditions of the Creative Commons Attribution license (http://creativecommons.org/licenses/by/4.0/). 